\title{
Effects of an active lifestyle on water balance
}

Gethin H Evans ${ }^{1}$, Ronald J Maughan ${ }^{2}$, Susan M Shirreffs ${ }^{3}$

1. School of Healthcare Science, Manchester Metropolitan University, Manchester M1 5GD, UK

2. Loughborough University, Loughborough, UK

3. Department of Medicine, St Andrews University, St Andrews, UK

\begin{abstract}
Water is the most abundant chemical constituent of the human body, typically making up approximately two thirds of body mass, but body water content is maintained within relatively narrow limits by a number of regulatory mechanisms. Both a reduction (hypohydration) and increase (hyperhydration) in body water may, if sufficiently severe, lead to adverse health and performance consequences. Active lifestyles, warm climates, and high altitude, as well as some infectious illnesses, increase the likelihood of becoming hypohydrated due to an increase in water loss. Moderate reductions in body water result in changes in cardiovascular system function as well as altering cognitive function and mood. A significant number of elite athletes, recreational exercisers and those with active occupations begin their daily activities in a hypohydrated state and incur large sweat losses during periods of activity, and thus risk negative effects on physiological function. Sweat rate and fluid intake during physical exertion are highly variable between individuals suggesting that an individual hydration strategy may be necessary to avoid significant levels of hypohydration. Rehydration after the completion of physical activity may also be necessary to avoid starting further bouts of activity in a hypohydrated state. Undertaking physical activity in a hypohydrated state appears to increase an individual's perceived exertion which may negatively influence exercise performance and self-selected exercise intensity, and may decrease the likelihood of further participation in physical activity. This is, therefore, an important consideration for public health as well as competitive sportspeople, be they elite or otherwise. Certain populations, such as the elderly, are more likely to become hypohydrated which may lead to other illnesses and contribute to morbidity and mortality.
\end{abstract}

\section{Key words}

Hydration; Hypohydration; Water Turnover; Physical Activity; Occupational Activity; Perceived Exertion; Exercise Performance; Exercise Participation; Overhydration 


\section{Key points}

Body water content is normally maintained within narrow limits by regulatory mechanisms affecting both intake and loss. Water balance is intimately linked with salt balance to regulate osmolality of body water compartments.

The physiological mechanisms that govern intake may be over-ridden by conscious control, resulting in disturbances of water and salt balance.

Transient modest disturbances in water balance are common and of little or no consequence. Both a reduction (hypohydration) and increase (hyperhydration) in body water content may, if sufficiently severe, lead to adverse effects on health and performance.

Water losses are increased by exercise and warm environments, but responses are highly individual. Undertaking physical activity in a hypohydrated state appears to increase an individual's perceived exertion which may negatively influence exercise performance and self-selected exercise intensity, and may decrease the likelihood of further participation in physical activity.

Certain populations, such as the elderly, are more likely to become hypohydrated which may lead to other illnesses and contribute to morbidity and mortality.

\section{Abbreviations}

ANP atrial natriuretic peptide

AVP arginine vasopressin

EFSA European Food Safety Authority

$\mathrm{mL} \quad$ millilitre

mosm milliosmole

RPE Rating of Perceived Exertion

$\mathrm{VO}_{2 \max }$ maximum oxygen uptake 


\section{Background}

Water is the most abundant component in the human body, except in the very obese, making up about $50-70 \%$ of body mass. Approximately two thirds of this water is found in intracellular compartments with the remaining third in extracellular compartments. Within the extracellular compartment, water is found in the interstitial fluid (approximately $15 \%$ of body mass) and the blood plasma ( $5 \%$ body mass). Despite the abundance of water in the human body, it is kept within relatively narrow limits. Euhydration is defined as a "normal" body water content, usually denoted by a plasma osmolality between 280 and 290 mosmol/kg although this increases with age (Institute of Medicine, 2005). The body water content fluctuates over the day as losses are continuous and intake is episodic, but it is normally maintained within about $\pm 0.2 \%$ of body mass in temperate conditions and within $\pm 0.5 \%$ when in the heat or during exercise (Greenleaf, 1992). Individuals are considered to be hypohydrated or hyperhydrated if values fall outwith these limits. Both of these conditions, if sufficiently severe, can impair all aspects of physiological function and may prove fatal in extreme cases.

\section{Water balance}

Water balance is achieved when water intake matches water losses, but water intake is episodic whereas water losses are continuous, so water balance fluctuates throughout the course of a day. Over a 24 hour period, water balance is generally maintained through normal physiological function. Avenues of water intake include fluid consumed through drinking and that found in ingested food with a small proportion generated via oxidative metabolism (Table 1). At rest and in temperate environments the main avenue of fluid loss is via urine production with some water lost via respiration, skin loss, sweating and faecal loss. During exercise and in hot environments, a greater proportion of water is lost via sweating in order to limit the rise of core temperature that occurs in these situations.

$<$ Table 1 around here $>$

Urine production is regulated by hormones including arginine vasopressin (AVP), aldosterone and atrial natriuretic peptide (ANP). AVP is secreted from the posterior pituitary and acts on the collecting ducts of the kidney to increase water reabsorption, leading to production of small volumes of concentrated urine. The main physiological factors that initiate the secretion of AVP are an 
increase in in plasma osmolality and a decrease in blood volume. A $1 \mathrm{mosm} / \mathrm{kg}$ change in plasma osmolality results in a $0.41 \mathrm{pmol} / \mathrm{L}$ change in AVP (Baylis, 1987) and a $3 \mathrm{mosm} / \mathrm{kg}$ change in plasma osmolality results in a $250 \mathrm{mosm} / \mathrm{kg}$ change in urine osmolality (Robertson, 1974). A change in blood volume of $7-10 \%$ is required for similar magnitudes of change in urine osmolality making plasma osmolality the main determinant of AVP release (Baylis, 1987). The renin-angiotensin aldosterone system is also activated in response to decreases in blood volume, with aldosterone acting on the collecting ducts of the kidney to increase sodium reabsorption which, in turn, leads to water reabsorption and the production of small volumes of concentrated urine. ANP is secreted from the right atrium in response to increased blood volume and leads to decreases in sodium reabsorption in the nephron and also inhibits renin secretion, leading in turn to an increase in urine sodium content and urine volume.

One of the main drivers for fluid intake is thirst, though much drinking behaviour is dictated by habit rather than stimulus-driven. Thirst is the result of a complex interaction between physiological, psychological and behavioural factors (Adolph, 1954). Changes in plasma osmolality and blood volume are thought to play important roles in the thirst response, thus the same factors that regulate water loss are also involved in water intake. Animal models have suggested that substances such as angiotensin 2, bradykinin and serotonin may also be involved in the thirst response. Recently, there have been some suggestions that genetic factors may also account for some variation in thirst response between individuals, although the picture is not entirely clear at present (Saunders et al. 2006; Yau et al. 2015). Generally, thirst is considered to be a poor indicator of short term deviations in body water, given observations that unlimited access to drinks after periods of fluid restriction tends not to fully restore water losses (Shirreffs et al. 2004) and rapid fluid ingestion in these circumstances appears to alleviate the perception of thirst before euhydration is restored and before major changes in circulating osmolality are observed (Rolls et al. 1980). The thirst response is considered, however, to be sufficient to restore body water levels over longer time periods.

The European Food Safety Authority (EFSA) has concluded that adequate total (i.e. water from food and fluid) daily water intake is 2.0 litres for an average adult female and 2.5 litres for an average adult male. Different adequate total water intakes are reported by the Institute of Medicine in the United States with values reported as 2.7 litres and 3.7 litres for adult females and males respectively. The values reported by these bodies are an average (or median) volume consumed by healthy adults and are, therefore, classed as adequate intakes rather than recommended intakes. Considerable variation in the volumes of water and other beverages habitually consumed by healthy adults is observed. For physically active individuals that will lose greater volumes of water via 
sweating, which is exacerbated in hot environments, achieving the adequate intakes reported is not a guarantee that water intake is sufficient for that individual. It is likely, however, that water intake throughout the day will match water losses due to a combination of habitual fluid intake and the individual's thirst response driving further fluid intake.

\section{Sweating, water balance and water turnover}

At rest, metabolic heat production is approximately 60 watts, but metabolic demand increases in a linear fashion and can reach 1 kilowatt during activities such as marathon running. This metabolic heat must be dissipated in order to avoid large increases in core temperature and this is met largely by an increase in sweat rate. The main factors that determine sweat rate are exercise intensity, duration and frequency as well as the environment in which physical activity is undertaken.

In recent years, a large number of studies have been undertaken to measure pre-exercise hydration status and to assess sweat rate loss and fluid replacement in physically active individuals. Most of these studies have focussed on elite athletes undertaking training sessions and/or competitive events in different environmental conditions. Maughan et al. (2004) studied elite football players during a training session in warm conditions and observed a median pre-exercise urine osmolality of $666 \mathrm{mosm} / \mathrm{kg}$ with a range of 103 to $1254 \mathrm{mosm} / \mathrm{kg}$. During exercise, median fluid intake was 971 $\mathrm{mL}$ with a range of 265 to $1661 \mathrm{~mL}$ and percentage body mass loss was $1.4 \%$ with a range of 0.5 2.6\%. In a similar study performed in a cold environment, Maughan et al. (2005) observed that preexercise urine osmolality was $872 \mathrm{mosm} / \mathrm{kg}$ (range: $481-1228 \mathrm{mosm} / \mathrm{kg}$ ), fluid intake was $420 \mathrm{~mL}$ (range: $44-950 \mathrm{~mL}$ ) and percentage body mass loss was $1.6 \%$ (range: $0.9-2.5 \%$ ). Similar results have been observed during competitive football matches (Maughan et al. 2007) and throughout a competitive handball tournament (Cunniffe et al. 2014). These studies demonstrate that some individuals are likely to begin exercise in a hypohydrated state, that there are large inter-individual differences in sweat rate and fluid intake during exercise and that some individuals are likely to become significantly dehydrated by undertaking relatively short but intense periods of physical activity. If such results are seen in elite performers with a large professional support team, it is likely that recreational athletes also experience similar or greater levels of hypohydration.

Sweat consists of water, minerals and organic components. Consequently, when sweat rate increases during exercise it is not just water that is lost: the main electrolytes lost via sweat are sodium and chloride at concentrations of approximately $15-80 \mathrm{mmol} / \mathrm{L}$. There is large interindividual variation in the composition of sweat leading to large variations in electrolyte and salt loss 
between individuals (Maughan et al. 2004; Maughan et al. 2005). Sweat is invariably hypotonic, however, and one effect of high sweat rates is to cause an increase in the osmolality of body fluids. The variability in sweat rate and sweat composition, in addition to the large individual variability in sweat loss, means that a single hydration strategy is not appropriate for all physically active individuals and hydration advice should be tailored to the individual in question.

Body water turnover, or the replacement of water lost over a given period, is approximately $5-10 \%$ of total body water content per day for a sedentary individual living in a temperate environment, but can increase to $20-40 \%$ if prolonged exercise is undertaken in a hot environment (Kenefick et al. 2012). Fractional water turnover is higher in children up to 15 years of age than in adults and higher in physically active individuals than in age-matched sedentary individuals (Shimamoto and Komiya, 2000). Leiper et al. (2001) reported that average median water turnover in a cool environment for a group of regular cyclists was $47 \mathrm{ml} / \mathrm{kg} / \mathrm{d}$ compared to $36 \mathrm{ml} / \mathrm{kg} / \mathrm{d}$ for a group of age-matched sedentary controls, with the difference in water turnover due primarily to non-renal water losses. When similar studies (Leiper et al. 1996) were undertaken in temperate environments, water turnover rates were higher $(4673 \mathrm{ml} / \mathrm{d})$ in recreational joggers than sedentary age-matched controls $(3256 \mathrm{ml} / \mathrm{d}$ ) but the difference was due to an increased renal loss rather than differences in sweat loss. This suggests that these individuals may have over-estimated their fluid requirements.

Physical activity comprises both voluntary exercise and occupational activity. In many cases, occupational activity may be performed in hot and humid environments or when wearing uniforms and/or personal protective equipment that prevent physical heat loss and restrict evaporation of sweat. Consequently, undertaking occupational activity in these situations will have an influence on hydration status and body water balance. While this may lead to health consequences such as heat stroke, it may also affect safety, productivity, worker morale and operating costs.

Brake (2001) monitored the hydration status, sweat rate and fluid intake of metal and coal miners. In a group of 64 miners tested at the start of their shift, only $41 \%$ were classed as having "good" or "fair" hydration status based on urine specific gravity measurements and were classed as fit to work in a thermally stressful environment. The remaining $59 \%$ were classed as unfit to work in this environment with $9 \%$ being classed as "clinically dehydrated". Further analysis of a cohort of 413 miners who were tested after the completion of their shift suggested that $86 \%$ of these workers were adequately hydrated. This would suggest that access to fluids during their working hours was sufficient in most cases. In a group of 39 miners, fluid intake over the course of a variety of shift lengths averaged $6.5 \mathrm{~L}$ with a range of 2.4 to $12.5 \mathrm{~L}$. Analysis of urine specific gravity measures at the start, middle and end of the shifts showed no change in hydration status which would suggest that 
fluid intake was adequate to meet sweat losses in these individuals. In a study of outdoor workers in North-West Australia, Miller and Bates (2007) reported that only $21 \%$ of 382 urine samples analysed before, during and after summer shifts were classed as "adequately hydrated" or "marginally adequately hydrated". $51 \%$ of workers were classed as "hypohydrated" with $16 \%$ classed as "clinically dehydrated". Similar findings were reported by Bates et al. (2010) when investigating expatriate workers in the Middle East during the summer months. Urine samples were collected from workers at four different working sites and the percentage of samples classed as "hypohydrated" varied from 14 to 31\%. Fluid intake in these individuals appeared to be sufficient to match sweat losses induced during occupational activity. The previous studies were undertaken in relatively high ambient temperatures, but Polkinghorne et al. (2013) recently reported that $58 \%$ of miners working in temperate conditions were classed as "hypohydrated" both before and after a shift. They also noted that miners that began their shift dehydrated were nearly three times more likely to end their shift dehydrated than if they started in an adequate hydration state. Interestingly, workers that were classed as hypohydrated for the entire shift were more likely to be obese and at risk of metabolic complications (as assessed by waist circumference measurements) than those that were adequately hydrated for the duration of their shift.

The evidence described suggests that a degree of hypohydration is common in workers beginning demanding occupational physical activity in both temperate and hot environmental conditions. While this increases the risk of heat illness as well as having several potential effects on work productivity, workers in these situations appear to have adequate access to fluids during the working period to match sweat loss and, therefore, avoid exacerbated levels of dehydration. It would appear, however, that attempts need to be made to avoid the number of workers reporting to the workplace with significant levels of dehydration.

In a study of forestry workers, a situation in which there may be limited access to fluids, Biggs et al. (2011) observed that $43 \%$ of 103 workers in autumn were dehydrated at the start of their shift and this increased to $64 \%$ at the end of the shift. Similarly, in winter $47 \%$ of 79 workers were dehydrated at the onset of work and $63 \%$ were dehydrated afterwards. This would suggest that, in this working environment, fluid intake was not sufficient to replace fluid losses although further studies have suggested that adequate hydration status is likely to be restored by the following morning (Roberts and Donnelly 2006) which would be expected as a result of longer term regulatory processes of water balance.

Miller and Bates (2010) set out a number of practical guidelines to assist in the avoidance of dehydration in manual workers. These include supplying workers with appropriate drinks containers 
both prior to and during manual labour, drinking 0.6-1.0 L of fluid in a 2-3 hour period, providing electrolyte replacement solutions when in hot environments, encouragement of rehydration after shifts and education of workers regarding monitoring of their hydration status. The observations and practical applications described above apply mostly to occupations that involve a high degree of manual labour, but this is not the case for most workers. Despite this, it appears that a significant number of more sedentary (or at least less physically active) workers also begin work with inadequate hydration levels and remain in this condition throughout the working day (Mears and Shirreffs 2015). While the risk of heat illness and other health issues is likely to be relatively low in these individuals this is still an issue to be considered in the workplace.

\section{Hydration status and performance}

A considerable volume of research has been undertaken to investigate the effects of deviations in body water on physical capacity. Case studies demonstrate that prolonged physical activity in challenging environmental conditions without fluid ingestion can lead to collapse, significantly impaired physiological function and hypernatraemia (Noakes, Mekler and Pedoe 2008). Similarly, other case studies demonstrate that extreme over-ingestion of fluid during exercise can also lead to impaired physiological function and hyponatraemia which can, in rare cases, prove to be fatal (Noakes et al. 2004). These studies demonstrate that large acute disturbances in body water can undoubtedly affect performance and physiological function, but such extreme disturbances are relatively rare. The relatively small deviations from normal body water levels that are normally encountered appear to have little effect on performance and/or physiological function. Given that the main issue related to physical activity and hydration status is the increased rate of sweating and consequent water loss, most research has focussed on the impact of dehydration on exercise performance rather than hyperhydration. Despite the volume of research, much debate still exists regarding the point at which a reduction in body water is likely to affect physiological function. This is primarily due to methodological issues in experimental design in this area.

Armstrong et al. (1985) observed that dehydration equivalent to about $1.8 \%$ of body mass on average induced via administration of a diuretic led to increases in running time and reductions in running velocity at distances of $1500 \mathrm{~m}, 5000 \mathrm{~m}$ and $10000 \mathrm{~m}$. Cheuvront et al. (2005) reported that total work performed during a 30 minute endurance exercise time trial in temperate conditions at $50 \% \mathrm{VO}_{\text {peak }}$ was less when participants were hypohydrated by $3 \%$ of their body mass than when they were euhydrated. Similarly, McConell et al. (1997) observed that endurance exercise 
performance in a temperate environment was reduced when participants were hypohydrated compared to when prior fluid replacement was allowed. Nybo et al. (2001) demonstrated that undertaking exercise in a dehydrated condition reduced $\mathrm{VO}_{2}$ max and time to fatigue in a warm environment when compared to a euhydrated condition. Similar observations have been reported by others (Barr et al. 1991; Below et al. 1995). A recent review by Cheuvront and Kenefick (2014) concluded that the majority of studies in this area have suggested that a reduction in body mass of $2 \%$ or more is likely to reduce endurance exercise performance particularly when that exercise is performed in a hot environment.

The effects of hypohydration on cardiovascular function have also been extensively studied. Gonzalez-Alonso et al. (1997) reported that stroke volume was reduced and heart rate increased in when participants were dehydrated and undertook exercise in a hyperthermic environment. This reflects at least in part the phenomenon of cardiovascular drift that has been reported to occur in prolonged exercise for at least 30 years (Nielsen et al. 1984; Roy et al. 2000). In addition to the impact of hypohydration on stroke volume and heart rate, Gonzalez-Alonso et al. (1998) have also reported a reduction in skin blood flow compared to the euhydrated state which could reduce the extent of heat loss and lead to increases in core temperature. An individual's rating of perceived effort (RPE) at a given exercise intensity has also been shown to increase when exercising in a hypohydrated state compared to a euhydrated state (Below et al. 1995; Murray et al. 1995; Baker et al. 2007) which is likely to be another mechanism by which a reduction in body water negatively influences exercise performance. Interestingly, a recent study by Fleming and James (2014) demonstrated that habituation to undertaking exercise in a hypohydrated state reduced the detrimental effects of a reduction in body water on endurance exercise performance. This effect was not mediated by changes in cardiovascular system function but apparently by habituation reducing RPE.

It has been suggested that a reduction in body water of $3-4 \%$ is required to induce detrimental effects on muscle function (Judelson et al. 2007). A recent meta-analysis of 28 articles (Savoie et al. 2015) concluded that hypohydration results in meaningful reductions in anaerobic power, muscle endurance and strength and that the method of inducing the reduction in body water and training status were important considerations. In particular, hypohydration induced by passive means resulted in less effect on muscular performance than those that involved an active component. This meta-analysis also concluded that body-weight dependent muscular performance, such as vertical jumping ability, may be improved by a reduction in body water of $3 \%$ or more. 
Relatively mild levels of hypohydration have been shown to negatively affect cognition. Many of the older studies in this area suffer from poor methodology, but recent studies use more robust methods. Watson et al. (2015) required participants to follow a drinking regimen that involved ingestion of $25 \%$ of suggested daily guidelines on the day prior to the trial, resulting in a reduction in body mass of $1.1 \%$. During a two-hour simulated driving task, a greater number of minor driving errors were recorded when participants were hypohydrated compared to when they performed the task having followed current drinking guidelines. Similarly, Lindseth et al. (2013) reported that flight performance and spatial cognition tests were reduced in pilots who were hypohydrated due to low levels of fluid ingestion compared to those who were euhydrated with adequate levels of fluid ingestion. Ganio et al. (2011) observed that mild hypohydration of approximately $1.5 \%$ body mass resulted in reduced cognitive aspects such as visual vigilance and visual working memory when compared to when euhydrated. These studies suggest that even mild levels of hypohydration appear to have a negative impact on cognition.

Body water deficits can be avoided or reversed only by ingestion of drinks or water-containing foods, so much attention has been given to the development of appropriate drinking strategies during exercise. As previously discussed, relatively small acute reductions in body water (as assessed by changes in body mass) are unlikely to cause any negative effects on performance and, therefore, a drinking strategy that restores all body water lost during exercise is unnecessary. Similarly, generic advice to all physically active individuals is not appropriate due to the large individual differences in sweat losses that occur during exercise. In such a situation, this guidance would be sufficient for some individuals, but would cause some to become hypohydrated and would lead to excessive ingestion for others, with the accompanying risk of hyponatraemia. Water and electrolyte losses can be assessed during training in response to different environmental conditions, and a drinking strategy implemented to avoid reductions in body water that may negatively influence exercise performance (Maughan and Shirreffs, 2008). Alternatively, individuals can drink only when thirsty (Noakes 2012) or ad libitum. While these last two strategies are similar they differ in that drinking to thirst relies solely on the thirst response to drive fluid intake whereas drinking ad libitum involves other external cues in addition to thirst response. Armstrong et al. (2014) compared a drinking to thirst strategy to an ad libitum strategy in trained cyclists completing a $164 \mathrm{~km}$ road cycle at an ambient temperature of 36 degrees. Although the percentage body mass lost and fluid intake was the same between the two groups, the authors concluded that an ad libitum strategy may be easier to implement as this involves less thought and consideration while exercising. 
It seems clear that a single hydration strategy is not appropriate for all individuals and numerous confounding factors need to be considered. These include the individual's water loss, individual preference of taste and familiarity with drinks, the ambient temperature, temperature of the drink and the carbohydrate and electrolyte content of the drink. An additional consideration is individual insusceptibility to gastrointestinal disturbance that may occur as a result of fluid ingestion during exercise. Relatively high intensity exercise $\left(>70 \% \mathrm{VO}_{2 \max }\right)$ reduces the rate at which fluid is emptied from the stomach (Leiper et al. 2001) as does ingestion of solutions with relatively high carbohydrate concentration (Vist and Maughan, 1994). Consequently, ingestion of large volumes of water and/or solutions containing carbohydrate during exercise may lead to gastric discomfort in some individuals. While there is some evidence that it is possible to train the gastrointestinal system to the ingestion of these volumes (Jeukendrup and McLaughlin, 2011), it is still an important consideration when planning hydration strategies during physical activity.

A body water deficit is normally present after after prolonged exercise, and there is a large body of research on post-exercise rehydration. If a single exercise session is completed during the day, there is no need for an aggressive rehydration strategy to be implemented as normal regulatory processes governing fluid intake will ensure that water balance is maintained over a 24 hour period. If a second exercise session is to be performed on the same day, a post-exercise rehydration strategy may be needed to ensure that euhydration is restored before the second session. The most important factors to consider are the volume and sodium content of fluid that is consumed. Shirreffs et al. (1996) observed that a volume greater than that lost during exercise is required to account for obligatory urine losses. This is typically translated as $1.5 \mathrm{~L}$ for every $1.0 \mathrm{~kg}$ of body mass lost during exercise. It also seems as though the rate at which fluid is ingested is an important consideration with high rates of fluid ingestion less effective at maintaining fluid balance over a recovery period than low rates of ingestion of the same volume (Kovacs et al. 2002). The composition of a rehydration solution is likely to alter the effectiveness of that solution to maintain fluid balance over a recovery period. The most important constituent of a rehydration solution is the sodium concentration as this is the most abundance ion in the extracellular fluid and, therefore, has a significant impact on plasma osmolality. The addition of sodium to a rehydration solution has been shown to improve its effectiveness at maintaining fluid balance during a recovery period (Shirreffs and Maughan 1998). The addition of carbohydrate and protein to a solution may also be of benefit as the addition of these nutrients reduces the rate of gastric emptying and overall water absorption ensuring that water loss is minimised due to the avoidance of large changes in plasma volume (Evans et al. 2009; James et al. 2011). An additional consideration is whether food is ingested alongside a solution. Water is not considered to be an adequate rehydration solution when ingested on its own 
as it is rapidly absorbed into the blood and causes a relatively large reduction in plasma volume and a diuresis (Nose et al. 1988), but when ingested alongside a meal containing adequate electrolytes, water may be a suitable rehydration solution (Maughan et al. 1996).

\section{Hydration for recreational activity}

Regular, moderate physical activity is known to induce numerous health benefits, and cardiorespiratory fitness is considered an independent risk factor for a number of disease states (Bouchard et al. 2015). Physical activity is therefore often prescribed to improve health. While physical activity alone does not appear to induce large degrees of weight loss, it does have beneficial effects on body composition and the incorporation of physical activity into a weight loss strategy that also includes restriction of energy intake is likely to produce the greatest degree of body mass loss (Wu et al. 2009). In addition, the extent of weight regain after a period of weight loss is likely to be lower if physical activity is incorporated into the initial weight loss strategy (Wang et al. 2008). An individual's rating of perceived exertion (RPE) during physical activity is a key regulator of selfselected exercise intensity and will likely determine whether that individual continues or terminates an exercise session. Consequently, factors that alter an individual's RPE during exercise are of interest to insure compliance with exercise strategies used to promote health.

The sensation of effort during exercise is a complex phenomenon involving numerous physiological, psychological and social factors (St Clair Gibson et al. 2003) and is typically assessed using a Borg scale (Borg, 1982). Briefly, the perception of effort during exercise involves integration of physiological mediators (such as ventilation, availability of energy substrate and skin temperature) with psychological factors (such as motivation, mood state and experience), exertional symptoms (such as heavy breathing and sweat rate) and, in the case of elite athletes, performance considerations, by the sensory cortex. This results in a perceptual response that will determine the perceived effort of exercise (Robertson and Noble, 1997). The strongest physiological mediators of RPE are respiratory rate, sensation of strain in muscles and joints, perception of body temperature and limb movement speed (Robertson and Noble, 1997). Given the close relationship between core body temperate, sweat rate, skin temperature and hydration status it is no surprise that there is interest in determining whether an individual's hydration status influences their perception of effort during exercise.

Few, if any, studies have been carried out specifically to study the effect of dehydration on RPE during exercise. Instead, RPE has been measured as a secondary outcome measure in studies 
examining the effect of dehydration on other markers of physiological function. In some of these studies, subjects began exercise in a dehydrated state while in others dehydration was induced by withholding fluids during exercise. Cheuvront et al. (2005) induced dehydration via heat 3 hours of heat exposure that resulted in a $3 \%$ reduction in body mass prior to undertaking a 30 minute exercise trial at $50 \% \mathrm{VO}_{2 \max }$ and a 30 minute time trial. No differences between in RPE were observed between the euhydrated or dehydrated states. Similarly, Kenefick et al. (2006) reduced body water by 1.7-1.8L via 75 minutes of exercise in hot conditions before a 75 minute heat tolerance test involving running exercise. During this heat tolerance test, there was little difference in RPE when participants were euhydrated than when dehydrated. In contrast, Riebe et al. (1997) induced a level of $4 \%$ dehydration via exercise in the heat before a period of rehydration or no fluid ingestion. During a subsequent exercise test, RPE was significantly higher in the dehydrated state than in the euhydrated condition. Similar findings of an increase in RPE when previously dehydrated compared to a euhydrated condition have been observed by Fleming and James (2013) and Gonzalez-Alonso et al. (1995). On balance, it would seem that beginning exercise in a dehydrated state is likely to lead to a small but meaningful increase in RPE.

Montain and Coyle (1992) showed an association between the extent of dehydration accrued during prolonged exercise in a warm environment and the RPE. Watson et al. (2006) reported a significant increase in RPE when participants undertook an intermittent exercise trial at $55 \% \mathrm{VO}_{2 \max }$ in hot conditions without fluid ingestion compared to when plain water was ingested to match sweat losses i.e. dehydration was allowed to accrue. Similarly, Baker et al. (2007) observed that 3 hours of treadmill walking without fluid replacement led to an increase in RPE in comparison to when fluid replacement was allowed. Ishijima et al. (2009) reported that 90 minutes of cycle exercise at 55\% $\mathrm{VO}_{2 \max }$ without fluid ingestion led to greater RPE than when exercise was undertaken with fluid ingestion. These observations would suggest that dehydration accrued while exercising for longer than 30 minutes may also lead to a small but meaningful increase in RPE.

Several mechanisms may explain why hypohydration may lead to an increase in RPE, including both physiological and psychological factors. As discussed previously, hypohydration leads to a reduction in stroke volume and an increase in heart rate (Gonzalez-Alonso et al. 1997) as well as a reduction in skin blood flow (Gonzalez-Alonso et al. 1998). In addition, a reduction in body water leads to a reduction in $\mathrm{VO}_{2 \max }$ with greater losses resulting in greater effects. Blood-brain-barrier permeability may be altered (Watson et al. 2006) and cerebral perfusion reduced (Carter et al. 2006) in response to hypohydration resulting in a direct effect on the central nervous system. Hypohydration also leads 
to dryness of the mouth, thirst and headaches which could ultimately affect mood state and psychological factors that alter the perception of effort (Shirreffs et al. 2004).

A substantial body of evidence therefore exists to suggest that starting exercise in a hypohydrated state or allowing hypohydration to occur during exercise results in an increased perception of effort. The effect of hypohydration on RPE is an important consideration for situations of occupational activity as well as the prescription of physical activity for health and wellbeing. Consequently, in these situations, individuals should be provided with the opportunity and education to ensure they are adequately hydrated prior to beginning work or an exercise session so that the effect of hydration status on RPE is not negatively influencing the activity in question.

\section{Hydration as part of a healthy lifestyle}

As outlined previously, moderate reductions in body water are common as a result of physically active lifestyles and these reductions may lead to changes in cardiovascular function as well as impairing cognitive processes and mood. These observations are important for physical performance in elite athletes as well as physically active members of the general public and for those with occupations that involve manual work. What is less clear, perhaps, is the effect of acute and chronic reductions in body water on health. The majority of work in this area has focussed on elderly populations.

Few studies have adequately examined the effects of hydration status on chronic disease, but there are some suggestions that a low fluid intake (and, therefore, hypohydration) may be linked to urinary stones (urolithiasis), constipation, bladder and colon cancer, hypertension and diabetic ketoacidosis (Manz and Wentz, 2012). These observations should be treated with caution, however, due to the lack of studies demonstrating causality.

The ageing process results in a reduction in fat-free mass, reduction in bone mass and a reduction in total body water as well as a blunted thirst response leading to an increased risk of hypohydration in older individuals. Hydration status is known to be a factor in disease progression for a number of medical disorders. Hypohydration is thought to predispose to infection which, in elderly populations, can be fatal in up to $50 \%$ of cases if not diagnosed early (Ferry, 2012). In an analysis of UK death certificates between 2005 and 2009, it was observed that 667 deaths were due to dehydration compared to 157 as a result of malnutrition: it is, however, difficult to determine whether dehydration was the causative factors in these deaths (Maughan et al. 2012). 
Leiper et al. (2005) observed that water turnover, as assessed via a deuterium oxide tracer, was significantly slower in elderly individuals living in a residential care home than those who lived at home. Similarly, Wolff et al. (2015) reported that $12 \%$ of elderly patients admitted to hospital from a residential care home were hypernatraemic upon admission compared to $1.3 \%$ of age-matched patients admitted from home. The extent of hypernatremia upon admission is related to likelihood of in-hospital mortality (Wolff et al. 2015) and, consequently, patients from residential care homes had a greater likelihood of in-hospital death than those who lived at home. Similar results were reported by El-Sharkawy et al (2015). These observations indicate that elderly individuals, particularly those in care homes, should be targeted by care workers to ensure adequate water ingestion and avoidance of hypohydration.

Quality of life is of primary importance in elderly individuals and is often assessed as a profile of physical, psychological, independence, social relationships, environmental and spiritual domains. In a study of 82 residents of Australian care homes, Courtney et al. (2009) reported that quality of life was positively correlated with clinical care indicators. The three main indicators that affected quality of life were poor hydration status, number of fall incidents and depression. These areas may be targeted to improve quality of life in residential care and improvements in hydration may be one of the easiest and most cost-effective ways to achieve this.

It seem clear from this evidence that certain populations, such as the elderly, are more susceptible to the impact that reductions in body water can have on health. Further evidence of this can be seen when examining the effects of changes in environmental temperature on morbidity and mortality. Sardon (2007) reported that temperatures throughout Europe were several degrees higher between June and September 2003 compared to other years. In an analysis of 2003 heatwave days compared to the years from 1990 to 2004, D'Ippoliti et al. (2010) observed that there were 8\% more deaths in Munich, $10 \%$ more deaths in London, $27 \%$ more deaths in Rome and $34 \%$ more deaths in Milan. In Mediterranean cities, where the heatwave had the largest impact on temperature, the percentage increase in all-cause mortality compared to other years was greatest in those aged $85+$ years and was higher in females than males. Similar observations have been made in Australia. Nitschke et al. (2007) analysed daily ambulance transports, hospital admissions and mortality over a 13 year period from 1993 and compared heatwaves to non-heatwave periods. Total mortal was unaffected during heatwaves, but ambulance transports and hospital admissions increased by $4 \%$ and $7 \%$ respectively. Total mental health and renal health hospital admissions were increased by $7 \%$ and $13 \%$ respectively. Similarly, Khalaj et al. (2010) surveyed 1,497,655 emergency admissions to hospital in sites across New South Wales. It was observed that on days of extreme heat, hospital admissions for 
heat illness, dehydration and electrolyte disturbance were increased whereas hospital admissions from other causes were not. Individuals with underlying medical conditions affecting the nervous, circulatory, respiratory and/or renal systems were particularly affected by the high environmental temperatures. It seems clear that certain populations, particularly the elderly and those with underlying medical conditions, are most at risk of high environmental temperatures and that this is likely to be at least partly due to the effect on hydration status.

Warren et al. (1994) examined the economic impact of hospital admissions due to hypohydration in US elderly adults. Almost 7\% of hospitalizations in 1991 had dehydration listed as a diagnosis with 1.4\% listed as the primary diagnosis. This resulted in US\$446 million (at 1991 prices) in Medicare claims suggesting that hypohydration-related hospital admissions have a significant economic impact. From these observations, it seems that the avoidance of hypohydration in these situations is a relatively straightforward but potentially effective intervention in certain populations for improving public health.

Much attention has been given to the acute and chronic effects of hypohydration, but large acute increases in body water, though less common than hypohydration, can also be hazardous. Overhydration can occur as a result of the ingestion of water in excess of the amount needed to maintain euhydration, an electrolyte deficit, and/or an inability of the renal system to compensate for these changes by appropriate adjustments of renal function (Hew-Butler et al, 2015). As with hypohydration, over-hydration is unlikely to lead to serious health consequences in healthy individuals, but occasionally it can be fatal. If the concentration of sodium in the extracellular space falls, water moves from the interstitial space into the cellular compartment, leading to swelling of cells. In most tissues this is of little consequence, though it may have implications for a number of cellular functions (Lang, 2011). If sufficiently severe, however, an increase in intra-cranial pressure will result and symptoms associated with "water intoxication", including headache, nausea, confusion and changes in behaviour, may appear. If intra-cranial pressure continues to increase, this can lead to central nervous system dysfunction, coma and death. Exercise associated hyponatremia, brought about by ingesting a greater volume of water than is lost via sweat, has been associated with several deaths and was reported in $13 \%$ of finishers of the Boston marathon in 2002 despite these individuals showing no clinical symptoms (Almond et al. 2005). A number of non-exercise cases of "water intoxication", brought on due to excessive fluid ingestion, have also been described. These include cases from fraternity initiation practices, co-ingestion of large volumes of fluid with recreational drugs such as MDMA, water ingestion during weight loss plans and social competitions involving large volumes of fluid intake (Hew-Butler et al, 2015). 


\section{Conclusion}

Despite the abundance of water in the human body, it is important to maintain levels within narrow limits. This is achieved by matching water intake and water output. An imbalance between water intake and output leads to either hypohydration or over-hydration. Chronic water imbalances are usually relatively mild: homeostasis will be restored due to normal regulatory processes. Acute imbalances can, if sufficiently severe, lead to changes in physiological function that can affect performance of physical activity and, in extreme cases, can lead to serious health consequences. Some elite athletes, exercisers and manual workers have been shown to begin activities in a hypohydrated state, even when there is a high risk of potentially harmful hypohydration. Sweat rates and fluid intake during physical activity both vary greatly between individuals. Undertaking physical activity in a hypohydrated state leads to an increase in subjective effort which may have an impact on exercise performance as well as self-selected exercise intensity. Some populations, such as the elderly, are more likely to become hypohydrated and they, and those who care for them, may need specific hydration advice in order to avoid potential adverse health consequences.

\section{References}

Adolph EF, Barker JP, Hoy PA. Multiple factors in thirst. Am J Physiol; 1954; 178: 538-562.

Almond CSD, Shin AY, Fortescue EB, Mannix RC, Wypij D, Binstadt BA, Duncan CN, Olson DP, Salerno AE, Newburger JW, Greenes DS. Hyponatremia among runners in the Boston marathon. New Eng J Med. 2005; 352: 1550-1556.

Armstrong LE, Costill DL, Fink WJ. Influence of diuretic-induced dehydration on competitive running performance. Med Sci Sports Exerc. 1985; 17: 456-461.

Armstrong LE, Johnson EC, Kunces LJ, Ganio MS, Judelson DA, Kupchak BR, Vingren JL, Munoz CX, Huggins RA, Hydren JR, Moyen NE, Williamson KH. Drinking to thirst versus drinking ad libitum during road cycling. J Athl Train. 2014; 49: 624-631.

Baker LB, Dougherty KA, Chow M, Kenney WL. Progressive dehydration causes a progressive decline in basketball skill performance. Med Sci Sports Exerc. 2007;39:1114-23.

Barr SI, Costill DL, Fink WJ. Fluid replacement during prolonged exercise: effects of water, saline, or no fluid. Med Sci Sports Exerc. 1991;23(7):811-7 
Bates GP, Miller VS, Joubert DM. Hydration status of expatriate manual workers during summer in the middle East. Ann Occup Hyg. 2010;54:137-43.

Baylis PH. Osmoregulation and control of vasopressin secretion in healthy humans. Am J Physiol. 1987; 253: R671-R678.

Below PR, Mora-Rodríguez R, González-Alonso J, Coyle EF. Fluid and carbohydrate ingestion independently improve performance during $1 \mathrm{~h}$ of intense exercise. Med Sci Sports Exerc. $1995 ; 27: 200-10$

Biggs C, Paterson M, Maunder E. Hydration status of South African forestry workers harvesting trees in autumn and winter. Ann Occup Hyg. 2011;55:6-15

Borg GAV. Psychophysical bases of perceived exertion. Med Sci Sports Exerc. 1982; 14: 377-381.

Bouchard C, Blair SN, Katzmarzyk PT. Less sitting, more physical activity, or higher fitness. Mayo Clin Proc. 2015; 90: 1533-1540.

Brake R. Fluid consumption sweat rates and hydration status of thermally-stressed underground miners and the implications for heat illness and shortened shifts (2001). Available at: http://www.qrc.org.au/conference/ dbase upl/2001 spk024 brake.pdf Accessed on March 7th 2016

Carter, R III, Cheuvront SN, Vernieuw CR, Sawka MN. Hypohydration and prior heat stress exacerbates decreases in cerebral blood flow velocity during standing. J Appl Physiol. 2006; 101: 1744-1750.

Cheuvront SN, Carter R III, Castellani JW, Sawka MN. Hypohydration impairs endurance exercise performance in temperate but not cold air. J Appl Physiol. 2005; 99: 1972-1976.

Cheuvront SN, Kenefick RW. Dehydration: physiology, assessment, and performance effects. Compr Physiol. 2014;4:257-85.

Courtney M, O'Reilly M, Edwards H, Hassall S. The relationship between clinical outcomes and quality of life for residents of aged care facilities. Aust J Adv Nurs. 2009; 26: 49-57.

Cunniffe B, Fallan C, Yau A, Evans GH, Cardinale M. Assessment of physical demands and fluid balance in elite female handball players during a 6-day competitive tournament. Int J Sport Nutr Exerc Metab. 2015;25:78-88. 
D’Ippoliti D, Michelozzi P, Marino C, de'Donato F, Menne B, Katsouyanni K, Kirchmayer U, Analitis A, Medina-Ramon M, Paldy A, Atkinson R, Kovats S, Bisanti L, Schneider A, Lefranc A, Iniguez C, Perucci CA. The impact of heat waves on mortality in 9 European cities: results from the EuroHEAT project. Env Health. 2010; 9: 37.

El-Sharkawy AM, P Watson, KR Neal, O Ljungqvist, RJ Maughan, O Sahota, DN Lobo. Hydration and Outcome in Older Patients admitted to hospital (The HOOP prospective cohort study) Age and Ageing 2015;44, 943-947

European Food Safety Authority (EFSA) Panel on Dietetic Products, Nutrition, and Allergies (NDA): Scientific Opinion on Dietary Reference Values for water. EFSA Journal. 2010; 8: 1459-1507.

Evans GH, Shirreffs SM, Maughan RJ. Post-exercise rehydration in man: the effects of osmolality and carbohydrate content of ingested drinks. Nutrition. 2009; 25: 905-913.

Ferry M. Strategies for ensuring good hydration in the elderly. Nutr Rev. 2005; 63: S22-S29.

Fleming J, James LJ. Repeated familiarisation with hypohydration attenuates the performance decrement caused by hypohydration during treadmill running. Appl Physiol Nutr Metab. 2014; 39:124-9.

Ganio MS, Armstrong LE, Casa DJ, McDermott BP, Lee EC, Yamamoto LM, Marzano S, Lopez RM, Jimenez L, Le Bellego L, Chevillotte E, Lieberman HR. Mild dehydration impairs cognitive performance and mood of men. Br J Nutr. 2011; 106: 1535-1543.

Gonzalez-Alonso J, Calbet JA, Nielsen B. Muscle blood flow is reduced with dehydration during prolonged exercise in humans. J Physiol. 1998; 513: 895-905.

Gonzalez-Alonso J, Mora-Rodriguez R, Below PR, Coyle EF. Dehydration reduces cardiac output and increases systemic and cutaneous vascular resistance during exercise. J Appl Physiol. 1995; 79: 14871496.

Gonzalez-Alonso J, Mora-Rodriguez R, Below PR, Coyle EF. Dehydration markedly impairs cardiovascular function in hyperthermic endurance athletes during exercise. J Appl Physiol. 1997; 82: 1229-1236.

Greenleaf JE. Problem: thirst, drinking behavior, and involuntary dehydration. Med Sci Sports Exerc, 1992;24:645-56. 
Hew-Butler T, Rosner MH, Fowkes-Godek S, et al. Statement of the 3rd International ExerciseAssociated Hyponatremia Consensus Development Conference, Carlsbad, California, 2015. Clin J Sports Med 2015; 25, 303-320.

Institute of Medicine (2005). Panel on Dietary Reference Intakes for Electrolytes and Water, Dietary Reference Intakes for Water, Potassium, Sodium, Chloride and Sulfate. Washington DC, The National Academies Press.

Ishijima T, Hashimoto H, Satou K, Muraoka I, Suzuki K, Hiquchi M. The different effects of fluid with and without carbohydrate ingestion on subjective responses of untrained men during prolonged exercise in a hot environment. J Nutr Sci Viaminol. 2009; 55: 506-510.

James LJ, Clayton D, Evans GH. Effect of milk protein addition to a carbohydrate-electrolyte solution ingested after exercise in the heat. Br J Nutr. 2011; 105: 393-399.

Jeukendrup AE, McLaughlin J. Carbohydrate Ingestion during Exercise: Effects on Performance, Training Adaptations and Trainability of the Gut. In. Maughan RJ, Burke LM. Sports Nutrition: More than just calories - Triggers for adaptation. Nestle Nutrition Institute Workshop Series. 2011; 69: 117.

Judelson DA, Maresh CM, Anderson JM, Armstrong LE, Casa DJ, Kraemer WJ, Volek JS. Hydration and muscular performance - Does fluid balance effect strength, power and high-intensity endurance? Sports Med. 2007; 37: 907-921.

Kenefick RW, Cheuvront SN, Leon LR, O'Brien KK. Dehydration and Rehydration. In: Auerbach PS (ed) Wilderness Medicine. Elsevier, USA. 2012. p 1393-1404.

Kenefick RW, O'Moore KM, Mahood NV, Castellani JW. Rapid IV versus oral rehydration: responses to subsequent exercise heat stress. Med Sci Sports Exerc. 2006; 38: 2125-2131.

Khalaj B, Lloyd G, Sheppeard V, Dear K. The health impacts of heat waves in five regions of New South Wales, Australia: a case-only analysis. Int Arch Occup Envrion Health. 2010; 83: 833-842. Kovacs EMR, Schmahl RM, Senden LMG, Brouns F. Effect of high and low rates of fluid intake on post-exercise rehydration. Int J Sports Nutr Exerc Metab. 2002; 12: 14-23.

Lang F. Mechanisms and significance of cell volume regulation. J Am Coll Nutr. 2007; 26(5 Suppl): 613S-623S. 
Leiper JB, Carnie A, Maughan RJ. Water turnover rates in sedentary and exercising middle aged men. Br J Sports Med. 1996;30:24-6.

Leiper JB, Broad NP, Maughan RJ. Effect of intermittent high-intensity exercise on gastric emptying in man. Med Sci Sports Exerc. 2001; 33: 1270-1278.

Leiper JB, Pitsiladis Y, Maughan RJ. Comparison of water turnover rates in men undertaking prolonged cycling exercise and sedentary men. Int J Sports Med. 2001;22:181-5.

Leiper JB, Primrose CS, Primrose WR, Phillimore J, Maughan RJ. A comparison of water turnover in older people in community and institutional settings. J Nutr Health Aging. 2005; 9: 189-193.

Lindseth PD, Lindseth GN, Petros TV, Jensen WC, Caspers J. Effect of hydration on cognitive function in pilots. Mil Med. 2013; 178: 792-798.

Manz F, Wentz, A. The importance of good hydration for the prevention of chronic diseases. Nutr Rev. 2005; 63: S2-S5.

Maughan RJ. Hydration, morbidity and mortality in vulnerable populations. Nutr Rev. 2012; 70: S152-S155.

Maughan RJ, Leiper JB, Shirreffs SM. Restoration of fluid balance after exercise-induced dehydration: effects of food and fluid intake. Eur J Appl Physiol Occup Physiol. 1996; 73: 317-325.

Maughan RJ, Merson SJ, Broad NP, Shirreffs SM. Fluid and electrolyte intake and loss in elite soccer players during training. Int J Sport Nutr Exerc Metab. 2004;14:333-46.

Maughan RJ, Shirreffs SM. Development of individual hydration strategies for athletes. Int J Sports Nutr Exerc Metab. 2008; 18: 457-472.

Maughan RJ, Shirreffs SM, Merson SJ, Horswill CA. Fluid and electrolyte balance in elite male football (soccer) players training in a cool environment. J Sports Sci. 2005;23:73-9.

Maughan RJ, P Watson, GH Evans, N Broad, SM Shirreffs. Water balance and salt losses in competitive football. Int J Sport Nutr Ex Metab. 2007;17:583-94.

Mears SA, Shirreffs SM. Assessing hydration status and reported beverage intake in the workplace. Am J Lifestyle Med 2015;9:157-68.

McConell GK, Burge CM, Skinner SL, Hargreaves M. Influence of ingested fluid volume on physiological responses during prolonged exercise. Acta Physiol Scand. 1997;160:149-56. 
Miller VS, Bates GP. The thermal work limit is a simple reliable heat index for the protection of workers in thermally stressful environments. Ann Occup Hyg. 2007;51:553-61.

Miller VS, Bates GP. Hydration, hydration, hydration. Ann Occup Hyg. 2010;54:134-6.

Montain SJ, Coyle EF. Influence of graded dehydration on hyperthermia and cardiovascular drift during exercise. J Appl Physiol. 1992; 73: 1340-1350.

Murray SR, Michael TJ, McClellan PD. The influence of fluid replacement rate on heart rate and RPE during exercise in a hot, humid environment. J Strength Cond Res. 1995;9:251-4.

Nielsen B, Sjogaard G, Bondepettersen F. Cardiovascular, hormonal and body-fluid changes during prolonged exercise. Eur J Appl Physiol Occup Physiol. 1984; 53: 63-70.

Nitschke M, Tucker G, R, Bi P. Morbidity and mortality during heatwaves in metropolitan Adelaide. Med J Aust. 2007; 187: 662-665.

Noakes TD. Commentary: role of hydration in health and exercise. BMJ. 2012; 345: e4171.

Noakes T, Mekler J, Pedoe DT. Jim Peters' collapse in the 1954 Vancouver Empire Games marathon. S Afr Med J. 2008;98:596-600.

Noakes TD, Sharwood K, Collins M, Perkins DR. The dipsomania of great distance: water intoxication in an Ironman triathlete. Br J Sports Med. 2004;38:E16.

Nose H, Mack GW, Shi XR, Nadel ER. Role of osmolality and plasma volume during rehydration in humans. J Appl Physiol. 1988; 65: 325-331.

Nybo L, Jensen T, Nielsen B, Gonzalez-Alonso, J. Effects of marked hyperthermia with and without dehydration on VO2 kinetics during intense exercise. J Appl Physiol. 2001;90:1057-64.

Polkinghorne BG, Gopaldasani V, Furber S, Davies B, Flood VM. Hydration status of underground miners in a temperate Australian region. BMC Public Health. 2013;13:426.

Riebe D, Maresh CM, Armstrong LE, Kenefick RW, Castellani JW, Echegaray ME, Clark BA, Camaione DN. Effects of oral and intravenous rehydration on ratings of perceived exertion and thirst. Med Sci Sports Exerc. 1997; 29: 117-124.

Roberts DF, Donnelly S. Fluid balance and sweat rates during strenuous physical labour by timber harvesters. Med Sci Sports Exerc. 2006;38:S173-4.

Robertson GL. Vasopressin in osmotic regulation in man. Annu Rev Med. 1974; 25: 315-322. 
Robertson R, Noble BJ. Perception of physical exertion: methods, mediators and application. Exerc Sport Sci Res. 1997;25:407-52.

Rolls BJ, Wood RJ, Rolls ET, Lind H, Lind W, Ledingham JGG. Thirst following water deprivation in humans. Am J Physiol. 1980; 239: R476-R482.

Roy BD, Green HJ, Burnett ME. Prolonged exercise following diuretic-induced hypohydration: effects on cardiovascular and thermals strain. Can J Physiol Pharmacol. 2000; 78: 541-547.

Sardon JP. The 2003 heat wave. Euro Surveill. 2007; 12: 226.

Saunders CJ, de Milander L, Hew-Butler T, Xenophontos SL, Cariolou MA, Anastassiades LC, Noakes TD, Collins M. Dipsogenic genes associated with weight changes during Ironman triathlons. Hum Mol Genet. 2006; 15: 2980-2987.

Savoie FA, Kenefick RW, Ely BR, Cheuvront SN, Goulet EDB. Effect of hypohydration on muscle endurance, strength, anaerobic power and capacity and vertical jumping ability: A meta-analysis. Sports Med. 2015; 45: 1207-1227.

Shimamoto H, Komiya S. The turnover of body water as an indicator of health. J Physiol Anthropol Appl Human Sci. 2000;19:207-12.

Shirreffs SM, Maughan RJ. Volume repletion following exercise-induced volume depletion in man: replacement of water and sodium losses. Am J Physiol. 1998;43:F868-75

Shirreffs SM, Merson SJ, Fraser SM, Archer DT. The effects of fluid restriction on hydration status and subjective feelings in man. Br J Nutr. 2004; 91: 951-958.

Shirreffs SM, Taylor AJ, Leiper JB, Maughan RJ. Post-exercise rehydration in man: Effects of volume consumed and drink sodium content. Med Sci Sports Exerc. 1996; 28: 1260-1271.

St Clair Gibson A, Baden DA, Lambert MI, Lambert V, Harley YXR, Hampson D, Russell VA, Noakes TD. The conscious perception of the sensation of fatigue. Sports Med. 2003; 33: 167-176.

Vist GE, Maughan RJ. Gastric emptying of ingested solutions in man: effect of beverage glucose concentration. Med Sci Sports Exerc. 1994;26:1269-73.

Wang XW, Lyles MF, You TJ, Berry MJ, Rejeski WJ, Nicklas BJ. Weight regain is related to decreases in physical activity during weight loss. Med Sci Sports Exerc. 2008; 40: 1781-1788. 
Warren JL, Bacon WE, Harris T, McBean AM, Foley DJ. The burden and outcomes associated with dehydration among US elderly, 1991. Am J Public Health. 1994; 84: 1265-1269.

Watson P, Black KE, Clark SC, Maughan RJ. Exercise in the heat: effect of fluid ingestion on bloodbrain barrier permeability. Med Sci Sports Exerc. 2006; 42: 2197-2204.

Watson P, Whale A, Mears SA, Reyner LA, Maughan RJ. Mild hypohydration increases the frequency of driver errors during a prolonged, monotonous driving task. Physiol Behav. 2015; 147: 313-318.

Wolff A, Stuckler D, McKee M. Are patients admitted to hospitals from care homes dehydrated? A retrospective analysis of hypernatremia and in-hospital mortality. J R Soc Med. 2015; 108: 259-265.

Wu T, Gao X, Chen M, van Dam RM. Long-term effectiveness of diet plus exercise interventions vs diet only interventions for weight loss: a meta-analysis. Obes Rev. 2009; 10: 313-323.

Yau MWA, Moss A, James L, Gilmore W, Ashworth JJ, Evans GH. The influence of angiotensin converting enzyme and bradykinin B2 receptor gene variants on voluntary fluid intake and fluid balance in healthy men during moderate intensity exercise in the heat. Appl Physiol Nutr Metab. 2015; 40: 184-190. 
Table 1: Typical values $(\mathrm{mL})$ of different avenues of daily water input and output for a $70-80 \mathrm{~kg}$ sedentary male living and working in a temperate environment.

\begin{tabular}{|c|c|c|c|}
\hline \multirow{2}{*}{$\begin{array}{c}\text { Water Intake } \\
\text { Variable }\end{array}$} & Volume (L) & Variable & Volume (L) \\
\hline Water consumption & 1.6 & Urine & 1.4 \\
\hline Water in food & 1.0 & Respiration & 0.3 \\
\hline Metabolic water production & 0.4 & Skin (transcutaneous) & 0.5 \\
\hline \multicolumn{2}{|c|}{} & Sweat & 0.7 \\
\cline { 3 - 4 } & & Faeces & 0.1 \\
\hline Total & 3.0 & Total & 3.0 \\
\hline
\end{tabular}

